
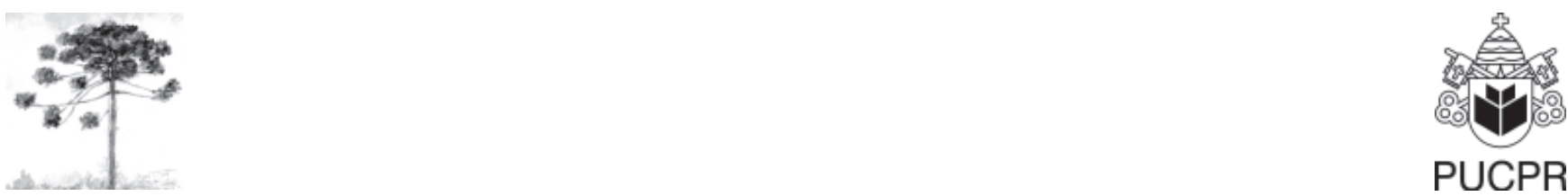

\title{
IMPORTÂNCIA MUSEOLÓGICA NA EDUCAÇÃO AMBIENTAL EM ESCOLAS: estudo de caso
}

\author{
Importance of the museum to environmental education in schools: case study
}

\author{
Alecksey Walewski \\ Biólogo Especialista, Secretaria de Estado da Educação do Paraná, Curitiba, PR - Brasil, e-mail: aleckseywalewski@yahoo.com.br
}

\section{Resumo}

Um museu de história natural aborda diversos ramos da biologia e das ciências e assim está diretamente relacionado à educação ambiental, sendo essencial num panorama de mudanças de hábitos e disseminação de conhecimento ambiental. Na elaboração de um museu se deve observar algumas questões técnicas relacionadas à preservação adequada dos exemplares, aos cuidados necessários com os experimentos, até a legislação vigente. Por outro lado, a integração dos alunos com o mundo da ciência proporciona uma nova perspectiva tanto aos educandos como para a própria educação, levando a uma nova postura ante a conscientização ambiental. No presente estudo, foi analisado o resultado da elaboração de um museu de história natural no ambiente escolar e suas consequências, a melhor forma de transmitir o conhecimento informal e a relações deste com o conhecimento formal. Esta relação reflete uma abordagem ainda incipiente em nosso país, mostrando a falta de base sólida na efetuação de práticas funcionais de educação ambiental no Brasil.

Palavras-chave: Museu; Educação; Educação ambiental.

\begin{abstract}
A museum of natural history boards several branches of the biology and of the sciences and so it is straightly connected to the environmental education, being essential in a view of changes of habits and dissemination of environmental knowledge. In the preparation of a museum it is necessary to observe some technical questions made a list to the appropriate preservation of the examples, to the necessary cares with the experiments, up to the legislation in force. On the other side to the integration of the pupils with the world of the science it provides a new perspective both to the students and for the education itself, leading to a new posture in front of the
\end{abstract}


environmental knowledge. In the present study there was analyzed the result of the preparation of a museum of natural history in the school environment and his consequences, the best form of transmitting the informal knowledge and to relations you gave with the formal knowledge. This relation reflects an approach still incipient in our country, showing the lack of solid base in the effectuation of functional practices of environmental education in Brazil.

Keywords: Museum; Education; Environmental education.

\section{INTRODUÇÃO}

O mundo atual, em processo de globalização, sofre grave crise socioambiental decorrente de diversos contrastes culturais, econômicos, políticos e científicos no processo de transição vigente. No combate desta faceta, os museus podem auxiliar a transmitir ideais que têm o potencial de adaptar a sociedade para este novo panorama global. O potencial educativo que um museu pode oferecer é de trazer à tona pontos de vista atualmente aceitos e submetê-los à discussão, além de manter viva parte do patrimônio que esta comunidade possui. A sociedade de hoje necessita da contribuição holística das diversas áreas do conhecimento na reflexãoação da problemática socioambiental. A formação de uma nova sociedade, ecologicamente correta e sustentável, é o ponto de partida na construção de cidadãos voltados para o bem comum, de ações de curto em longo prazo, para todos os habitantes deste planeta. $\mathrm{Na}$ adequação de uma população mais adaptada às novas realidades, a educação tem papel chave como meio de transformação. Esta tarefa é grande demais para ficar no âmbito escolar, somente será viável com a união de várias instituições educativas (sendo estas formais e não-formais), trabalhando juntas no intuito da construção dessa nova realidade socioambiental tão necessária (1).

$\mathrm{Na}$ atual conjuntura mundial, não há como separar o ensino de ciências da educação ambiental, sendo esta educação entendida pela Unesco (2): “A finalidade da educação ambiental é formar uma população mundial consciente e preocupada com o ambiente e problemas com ele relacionados, e que possua os conhecimentos, as capacidades, as atitudes, a motivação e o compromisso para colaborar individual e coletivamente na resolução de problemas atuais e na prevenção de problemas futuros”.

Um museu, sendo uma ferramenta de educação informal, pode proporcionar ao visitante uma oportunidade de promover interações sociais que permitam o ensino de determinado conteúdo, tornado possível realizar atividades que tornem o conhecimento das ciências mais acessível e eficiente à sociedade (3). Sustenta-se a temática museal em quatro pilares essenciais de sua existência: coletar, preservar, pesquisar e expor publicamente. Existem diversos tipos de coleções museológicas que dependem da finalidade, da amostra, estrutura, perfil do usuário, instituição à qual estão incorporadas etc., porém, um tipo especial são as coleções didáticas (4). Como cita Papavero (5): "O aprendizado é mais efetivo eimediato quando os interessados encontramse face ao material objeto de estudo".

Outro aspecto interessante é citado por Almeida, Ribeiro-Costa e Marinoni (6), sendo que qualquer que seja o estudo científico é vital não descartar amostras biológicas e sim depositar exemplares representativos em museus e instituições científicas que possuam infraestrutura apropriada para sua preservação. Assim, como é conhecido, as escolas são focos de depósito de material biológico, portanto, é preciso ter o cuidado de encaminhar ou preservar corretamente o material encontrado nessasinstituições. Auricchio (7) cita que para material de origem animal (mas que podemos estender para todos os outros grupos de seres vivos) uma coleção zoológica agrupa de forma organizada amostras de populações animais, partes ou produtos destes e dados associados a estas peças, visando o aproveitamento científico e, consequentemente, da sociedade. Papavero (5) cita que toda coleção tem importância didática, uma vez que a sua utilização sempre implica em atualização e geração de conhecimento, e contribui para a contínua capacitação de pessoal. Isto não implica que o material de uma coleção científica seja utilizado indiscriminadamente para treinamento de aprendizes, pois, certamente, este procedimento dilapidará rapidamente o acervo, provocando perda de peças de importância inestimável. Deste modo, as instituições que desenvolvem atividades de ensino geralmente possuem coleções didáticas, compostas por materiais 
sem procedência, excedentes, parcialmente danificados e especialmente adquiridos ou preparados para esta finalidade, que não estariam adequados para a incorporação numa coleção científica.

A destruição de ambientes naturais está em primeiro lugar como razão para o desaparecimento de espécies silvestres. É de saber comum que muitas espécies ainda não descritas podem nunca ser descritas pela sua extinção antes de serem cientificamente analisadas. As coleções biológicas possuem a razão de amostrar significantemente populações naturais para o estudo científico, atual ou futuro, no intuito de fins descritivos, comparativos, conservacionistas, econômicos, epidemiológicos, etc. Amostrar é vital para que essas atitudes possam ser tomadas e é essencial para se conhecer o que existe, para tanto, a amostragem deve ser contínua ao longo do espaço e do tempo.

Com a introdução das novas tecnologias, o papel do professor precisa mudar, pois o ensino tradicional (baseado no quadro negro e na explanação oral dos conteúdos) está focado no professor enquanto transmissor de saberes; com o uso da educação não formal obtida em um museu, por exemplo, o foco de informações passa a ser o material de estudo in loco, "informação é o fato, é o dado que encontramos nas publicações, na Internet ou trocando informações. O conhecimento é a informação interpretada, relacionada e processada" (8). Cabe então ao professor saber utilizar estas novas observações e trabalhar com o que foi observado no museu, para transformar essas informações recentes em conhecimento.

\section{DESENVOLVIMENTO}

A cidade de Piraquara, por possuir uma posição biogeográfica privilegiada, pois é uma região de ecótone, mostra enorme biodiversidade dentro de remanescentes de floresta ombrófila mista e grandes áreas conservadas de floresta ombrófila densa. Estrategicamente, é interessante o aproveitamento adequado dos exemplares que são encontrados mortos neste local ou que podem ser depositados, assim montou-se um Museu de História Natural, elaborando experimentos, amostrando a flora e a fauna locais para demonstração à população regional do que é de conhecimento científico, visando sua popularização e divulgação.
O Museu de História Natural da Serra do Mar (MHNSM), fundado em 9 de junho de 2006, localiza-se no antigo laboratório do Colégio Estadual Professor Mário Brandão Teixeira Braga, em Piraquara, Paraná. Tal colégio é o maior do município de Piraquara, tanto pelo número de alunos (1.622 estudantes de ensino fundamental e médio), pelo número total de 56 turmas, quanto por tamanho total, de $11.000 \mathrm{~m}^{2}(9)$.

Observando as características peculiares do Colégio, o MHNSM possui as intenções de: formar, manter e ampliar constantemente coleções biológicas; expor experiências científicas; ser centro de pesquisas científicas; atender a comunidade científica; organizar e manter uma biblioteca especializada; promover a divulgação da biologia e das ciências; colaborar com entidades científicas afins; dentre outros.

As exposições permanentes que o MHNSM dispõe até a data em questão são: um aquário de 320 litros reproduzindo o ecossistema limnológico local; terrário com um macho e uma fêmea de Cavia porcellus (porquinho-da-índia); uma gaiola com sete indivíduos de Melopsittacus undulatus (periquitos australianos); maquete tridimensional do sistema solar, em duas proporções: distância relativa do sol e diâmetro dos corpos celestes, que ocupa todo o teto do MHNSM, no qual os planetas ficam suspensos; exemplares depositados em conservante líquido; uma modesta coleção entomológica didática; alguns vertebrados taxidermizados; fósseis originários da região de Jaguaraíva, Paraná; esqueletos de alguns vertebrados; e um destilador. Ressalta-se que as construções de outras exposições permanentes e aumento do acervo das coleções já existentes estão em andamento.

$\mathrm{Na}$ produção dos discursos expositivos, deve-se atentar para as especificidades da cultura museal e do público visitante; elementos espaciais, temporais e objetos são considerados alguns fatores que irão constituir o diferencial da educação no museu (4). Observou-se que textos de caráter quantitativo como, por exemplo, as dimensões dos planetas e sua respectiva distância do Sol são informações que raramente são lidos, em contrapartida, curiosidades sobre os planetas são informações que chamam mais atenção do público que o museu atende principalmente: crianças, jovens e adolescentes.

Com base nas observações realizadas, retruca-se a afirmação de que na divulgação da ciência ocorre uma completa distorção e simplificação do conhecimento científico, pois o que ocorre é uma 
forma de tradução da linguagem científica para uma linguagem que a população em geral compreenda. Se esta tradução for bem elaborada e se possível exemplificada, trazendo para a realidade e cotidiano do público leigo, não há distorções, tampouco simplificações, apenas outro modo de repassar o mesmo conteúdo. Novos saberes são produzidos pelas relações que ocorrem dentro da cultura museal, assim, os processos de modificações do conhecimento científico com fins de ensino e divulgação não são simples simplificações (10).

Com o objetivo de transpor didaticamente a cultura museal para a comunidade, estão sendo realizados o "Clube de Astronomia" (desde março de 2006) e o projeto "Eco-escola sustentável" (desde março de 2006). O "Clube de Astronomia" tem por finalidade a inclusão científica em astronomia e o projeto "Eco-Escola sustentável" tem especificamente a intenção de educação ambiental. O projeto de "Eco-escola sustentável" pretende realizar a reciclagem da maior quantidade possível de resíduos sólidos produzidos no colégio, construir um biodigestor, elaborar uma composteira com os resíduos orgânicos provenientes do lanche escolar e da cantina, elaborar uma horta orgânica, construir um sistema de captação de água pluvial, efetuar florestamento da cobertura vegetacional original em larga escala de toda área viável do colégio e em seus arredores, construir um sistema de geração de energia elétrica não poluente e buscar formas de economia dos diversos recursos utilizados no ambiente escolar. Para tanto, o projeto utiliza como linha diretora a aplicação da educação ambiental na divulgação e demonstração de todas as ações propostas. Esses projetos vão de encontro às ideias de Vasconcelos e Guimarães (1).

[...] o museu deve aliar informação, ensinoaprendizagem e entretenimento em prol da promoção da ampliação da cultura e construção de valores. Valores que possibilitem o aumento do empoderamento da população, a partir da ampliação do exercício da sua cidadania. Para isso ele deve também trabalhar para desmitificar a Ciência emotivaropensamento problematizadorcrítico e investigador na compreensão-ação dos problemas sócio-ambientais.

Comumente existe uma grande separação da escola (e o saber escolar), que estabelece que cada etapa da apropriação do conhecimento escolar é determinada por rotinas prontamente estabelecidas, a participação dos estudantes em sala de aula molda uma postura mais passiva, e da instituição museológica (e o saber museal), obtido da modificação do saber científico, relação com temas que normalmente estão fora das diretrizes escolares, a participação dos estudantes no museu molda uma postura mais livre, sem rotinas preestabelecidas. $\mathrm{O}$ museu deve ser relacionado como uma alternativa à prática pedagógica, um local alternativo de aprendizagem, assuntos abordados no museu podem ser apresentados de um modo interdisciplinar ou focando a realidade dos alunos (11). No MHNSM, observouse que a vantagem do ambiente museal sempre atuante e presente na escola é o fato de o museu poder tratar de questões educacionais carentes e/ou deficientes na escola, pois o museu possui certa autonomia em suas exposições e ações, podendo em momentos oportunos realizar diferentes interpretações e práticas pedagógicas, pois cada instituição possui uma lógica e culturas próprias.

Exemplificando estas afirmações, temos o projeto de florestamento, que aos poucos vem sensibilizando professores, funcionários, alunos e pais no tocante à importância e qualidade de vida de coberturas vegetacionais. Atualmente conta-se com aproximadamente 400 mudas para o florestamento do colégio, sendo duas espécies produzidas pelo próprio museu e seis obtidas por um programa do Governo do Estado do Paraná de recuperação de mata ciliar. Outro ponto é a reciclagem que começou com a separação e venda do papel produzido pelos alunos na sala de aula e hoje temos a separação e arrecadamento de todo o resíduo sólido produzido por eles. No período de fevereiro de 1997 a dezembro de 1997, foi vendida uma tonelada e 156, 5 quilos de material reciclável, gerando uma renda anual de 499,54 reais, que foram aplicados no próprio MHNSM.

\section{CONCLUSÕES}

A existência de um museu de história natural é uma grande contribuição para sanar a carência intelectual e cultural que aflige diversos municípios, como o de Piraquara, conscientizando sobre a relevância da preservação e conhecimento da fauna e flora brasileiras, realizando ampla inclusão científica e mostrando a necessidade de transformação de uma sociedade mais humana. 
O processo de aprendizado e incorporação de novas informações é maximizado quandose utilizam práticas que trabalham com exemplares e/ou simulam fenômenos da natureza. Assim, é fundamental no processo de aprendizagem a visualização do objeto pesquisado como instrumento didático para a incorporação de novas informações. Afinal como iremos preservar se não é de conhecimento comum o que existe e os riscos reais de perda?

Um material tombado não é um patrimônio privado, mas da humanidade, porém, sob a tutela de um órgão. E entende-se por patrimônio da humanidade, qualquer bem da atualidade que pertence ao coletivo no tempo presente e também das gerações futuras. Sendo, portanto, nosso dever e obrigação deixar tal legado para a humanidade e conscientizar as gerações futuras.

\section{REFERÊNCIAS}

1. Vasconcellos MMN, Guimarães M. Educação ambiental no museu de astronomia. [acesso 30 ago. 2007]. Disponível em: www.redpop.org/ 8reunion/9rrp_ponenciais/

2. UNESCO. Tendances de l'education relative a l'environnement aprés. Tblisi, Paris: Unesco; 1977.

3. Gaspar A. Experiências de ciências para o ensino fundamental. São Paulo: Ática; 2003.

4. Marandino MA. A biologia nos museus de ciências: a questão dos textos em bioexposições. Ciência e Educação. 2002;8(2):187-202. [acesso 29 out. 2008]. Disponível em: http:// www.geenf.fe.usp.br/publica.php

5. Papavero N. Fundamentos práticos de taxonomia zoológica: coleções, bibliografia, nomenclatura. Museu Belém: Paraense Emílio Goeldi e Sociedade Brasileira de Zoologia; 1983.

6. Almeida LM, Ribeiro-Costa CS, Marinoni L. Manual de coleta, conservação, montagem e identificação de insetos. Ribeirão Preto: Holos, 2003.

7. Auricchio P, Salomão MG. Técnicas de coleta e preparação de vertebrados para fins científicos e didáticos. Arujá: Instituto Pau Brasil de História Natural; 2002.
8. Rodrigues GM. Novas tecnologias e o papel do professor. Folha de São Paulo, São Paulo, 22 de março de 2000. [acesso 29 out. 2008]. Disponível em: http:/ / www.milenio.com.br/aeee/ professores/Novas $\% 20$ tecnologias $\% 20 \mathrm{e} \% 200 \%$ 20papel $\% 20 \mathrm{do}^{2} \% 20$ professor.htm

9. Secretaria Educacional do Estado do Paraná Portal educacional do Estado do Paraná, Curitiba, 2003. [acesso 14 ago. 2008]. Disponível em: http://www4.pr.gov.br/ escolas/dadosEscola.jsp

10. Marandino MA. Pesquisa educacional e a produção de saberes nos museus de ciências. História, Ciência, Saúde-Manguinhos. 2005;12(suplemento):161-81. [acesso 29 out. 2008]. Disponível em: http:// www.geenf.fe.usp.br/publica.php

11. Marandino MA. Interfaces na relação museuescola. Cad. Cat. Ens. Fís. 2001;18(1):85-100. [acesso 29 out. 2008]. Disponível em: http:// www.geenf.fe.usp.br/publica.php

Recebido: 06/07/2007 Received: 07/06/2007

Aprovado: 20/09/2007 Approved: 09/20/2007 